\title{
A prospective study of the development of coronary heart disease in a group of 1202 middle-aged men
}

\author{
MARY GREIG, JOHN PEMBERTON, IRIS HAY, AND GILBERT MACKENZIE \\ From the Department of Community Medicine, Queen's University, Belfast
}

SUMmARY A prospective study of the development of coronary heart disease (CHD) in men aged 45-54 was conducted in six group practices in Belfast, Northern Ireland. Of the 1343 men examined once by clinical, electrocardiographic, biochemical, and anthropometric methods, 1202 free from CHD entered the prospective study. All 1202 men were followed for at least five years and the average annual incidence of CHD during this period was estimated as $1.73 \%$ (104 men developed). Of the 28 measurements made at initial examination, four-S-T depression, total lifetime tobacco consumption, diastolic blood pressure, and height (significant on classical linear discriminant function analysis)-were investigated in more detail. Using multidimensional contingency table methods, the probability of developing CHD was found to depend, in rank order of importance, on S-T depression, total lifetime tobacco consumption, and diastolic blood pressure. The risk of development was maximal $(0 \cdot 3732$, four times the 'random' risk) in men with S-T depression, greater than average total lifetime tobacco consumption, and a diastolic pressure of $100 \mathrm{~mm} \mathrm{Hg}$ or more.

Prospective epidemiological studies make it possible to measure the influence of personal and environmental factors which precede the emergence of CHD. A number of these studies conducted mainly outside the United Kingdom have now reported, and several so-called 'risk factors' have been identified. The present study, which utilises selected general practices in Belfast, was started in 1964 at a time when few projects of this type were being attempted on a community basis in the United Kingdom. The aim of the study was to identify social and biological characteristics of middle-aged men associated with an increased risk of developing CHD.

\section{Methods}

POPULATION STUDIED

This comprised all men born in the 10 -year period 1909-18 (that is, those aged $45-54$ at the beginning of the study) who were registered in six group practices in Belfast. These practices were chosen because the GPs concerned were prepared to co-operate in the study and a name-age-sex register was available for each practice. Subjects were sent a letter from their GPs explaining the purpose of the study and inviting their co-operation. Non-responders were sent a second letter after a month had passed. Those who still failed to respond were visited at home by MG before the subject was classed as a refusal, untraced, or unfit for examination. All the subjects were men of working age and the great majority were well and at work. This, and the fact that the examination was concerned with the heart, necessitating attendance at a health centre preferably during working hours, led to some reluctance to attend for examination and to a good many refusals. The examinations started in 1964 after a pilot study and additional practices were included up to 1968 . Men born in the period 1909-18 who were examined late in the study were therefore older than those examined at the beginning and some may have died from CHD before being called for examination.

All subjects have now been followed up for at least five years and some for as long as $\mathbf{1 2}$ years. In this report we deal with the five-year follow-up and relate the CHD status at five years to the findings at the initial examination. Table 1 shows the derivation of the sample of 1202 men who were finally included in the five-year follow-up study. All those who at the initial examination gave a history of angina of effort ${ }^{1}$ or who had had a confirmed myocardial infarction (141 in all) were excluded. All but 46 of the initial examinations and all the follow-ups were carried out by one observer (MG). 
Table 1 Derivation of sample of men born in the 10-year period 1909-18

\begin{tabular}{|c|c|c|c|c|}
\hline $\begin{array}{l}\text { Total number of men aged } 45-54 \text { on } \\
\text { the six practice registers }\end{array}$ & & & 1943 & $(100 \cdot 0)$ \\
\hline \multicolumn{5}{|l|}{ Exclusions } \\
\hline Refusals & 357 & $(18 \cdot 4)$ & & \\
\hline Untraced & 83 & $(4 \cdot 3)$ & & \\
\hline Unfit & 74 & $(3 \cdot 8)$ & & \\
\hline Transferred & 21 & $(1 \cdot 1)$ & & \\
\hline \multirow[t]{2}{*}{ Incomplete data } & 65 & $(3 \cdot 3)$ & & \\
\hline & 600 & $(30 \cdot 9)$ & & \\
\hline Initial examinations carried out & & & 1343 & $(69 \cdot 1)$ \\
\hline Subjects with evidence of CHD & & & 141 & $(7 \cdot 3)$ \\
\hline Present angina & 86 & $(4 \cdot 4)$ & & \\
\hline Past angina & 4 & $(0 \cdot 2)$ & & \\
\hline History of myocardial infarction & 51 & $(2 \cdot 6)$ & & \\
\hline $\begin{array}{l}\text { Subjects without evidence of CHD and } \\
\text { used in five-year prospective survey }\end{array}$ & & & 1202 & $(61 \cdot 9)$ \\
\hline
\end{tabular}

Percentages in brackets

Table 2 Distribution by civil state of the men examined compared with all men in Belfast aged 50-59(1966 census)

\begin{tabular}{lrrrrr}
\hline & \multicolumn{2}{c}{ Sample } & & \multicolumn{2}{l}{ Belfast } \\
\cline { 2 - 3 } \cline { 5 - 6 } Civil state & \multicolumn{1}{c}{ No. } & \multicolumn{1}{c}{$\%$} & & No. & \multicolumn{1}{l}{$\%$} \\
\hline Single & 85 & $(6 \cdot 3)$ & & 2781 & $(12 \cdot 7)$ \\
Married & 1218 & $(90 \cdot 7)$ & & 18124 & $(82 \cdot 9)$ \\
Other & 40 & $(3 \cdot 0)$ & & 954 & $(4 \cdot 4)$ \\
Total & 1343 & $(100)$ & & 21859 & $(100)$ \\
\hline
\end{tabular}

$x^{2}=65.77 \quad$ df $=2 \quad P<0.001$

Because the practices were not randomly selected, the question arises of the representativeness of these men in relation to the general population. The distributions of the sample by social class and civil state were examined for this purpose.

Table 2 shows that the sample differed from the population of Belfast with regard to distribution by marital state. The small proportion of single men in the sample may have been due to the greater difficulty of contacting single men of these ages and persuading them to come for a medical examination.
Information on social class distribution of men in Belfast was not obtainable. A comparison was therefore made with men in Northern Ireland (Table 3 ). The Table shows that the study sample differed somewhat from the population of Northern Ireland men of similar age in the distribution by social class. There was a larger proportion of men in Social Classes I and III and a smaller proportion in Social Classes IV and V in the sample. The results with regard to the incidence of $\mathrm{CHD}$ or the frequency of the various factors cannot therefore be assumed to be true for the whole male population of Northern Ireland or Belfast.

\section{VARIABLES STUDIED}

These included the 15 continuous and 13 categorical measurements listed in Table 4. Total lifetime tobacco consumption was estimated by multiplying daily consumption in grams by duration of smoking and aggregating the amounts for the different periods of the man's smoking life. The systolic and diastolic blood pressures were measured with the subject sitting after 10 minutes rest. The neuroticism and introversion scores were derived from answers to personality inventory questionnaire. ${ }^{2}$ Weight was measured to the nearest $0.5 \mathrm{~kg}$. with the man in socks and trousers only, with pockets empty, and height was measured to the nearest $1.0 \mathrm{~cm}$ with the man in socks. The skinfold thickness was measured with the Harpenden caliper ${ }^{3}$ at six sites: the mid-point of the posterior surface of each upper arm, over the inferiofe angle of each scapula, and two inches above each anterior superior iliac spine. The mean of the six measurements was used. A non-fasting sample of $10 \mathrm{ml}$ of venous blood was centrifuged at $1700 \mathrm{rpm}$ for one hour to remove particulate lipids ${ }^{4}$ and the serum cholesterol, ${ }^{5}$ total fatty acid, ${ }^{6}$ and alpha beta lipoprotein ratio $^{7}$ were estimated. Haemoglobin concentrations were estimated for all subjects in order to exclude cases of angina pectoris attributable to anaemia. One subject was excluded for that reason. Subjects were classified by social class, socioeconomic group, and economic position

Table 3 Distribution by social class of the sample of men examined compared with men of similar age in Northern Ireland in 1971

\begin{tabular}{|c|c|c|c|c|c|c|}
\hline \multirow[b]{2}{*}{ Social Class } & \multicolumn{2}{|c|}{ Sample } & \multicolumn{2}{|c|}{$\begin{array}{l}\text { Northern Ireland age groups } \\
45-54\end{array}$} & \multicolumn{2}{|l|}{$55-59$} \\
\hline & No. & $\%$ & No. & $\%$ & No. & $\%$ \\
\hline I & 67 & $(5 \cdot 0)$ & 2681 & (3.4) & 1089 & (3.1) \\
\hline $\begin{array}{l}\text { II } \\
\text { III }\end{array}$ & 324 & $(24 \cdot 1)$ & 19624 & $(25 \cdot 2)$ & 9355 & $(26.4)$ \\
\hline $\begin{array}{l}\text { III } \\
\text { IV }\end{array}$ & 695 & $(51 \cdot 8)$ & 30813 & $(39 \cdot 6)$ & 12356 & $(34 \cdot 8)$ \\
\hline $\begin{array}{l}\text { IV } \\
\text { V }\end{array}$ & 176 & $(13 \cdot 1)$ & 14713 & (18.9) & 7192 & $(20 \cdot 3)$ \\
\hline $\begin{array}{l}\mathbf{v} \\
\text { Unclassified }\end{array}$ & 81 & $(6.0)$ & 9655 & $(12 \cdot 4)$ & 5364 & $(15 \cdot 1)$ \\
\hline Unclassified & 0 & $(0.0)$ & 400 & $(0.5)$ & 147 & $(0.4)$ \\
\hline Total & 1343 & $(100 \cdot 0)$ & 77886 & $(100 \cdot 0)$ & 35503 & $(100 \cdot 1)$ \\
\hline
\end{tabular}


Table 4 Factors studied

\begin{tabular}{lll}
\hline Continuous measurements & Categories \\
\hline 1. Age & 16. Civil state \\
2. Total tobacco consumption & 17. Social class \\
3. Current tobacco consumption & 18. Socioeconomic group \\
4. Systolic blood pressure & 19. Economic position \\
5. Diastolic blood pressure & 20. Physical activity \\
6. Neuroticism score & 21. Alcohol drinking habit \\
7. Introversion score & 22. Arcus lipoides \\
8. Weight & 23. & Q/QS \\
9. Height & 24. T-wave changes \\
10. Skinfold thickness & 25. S-T wave changes \\
11. Serum cholesterol & 26. Current cigarette smoking \\
12. Serum total fatty acids & 27. Mother alive or dead \\
13. Alpha beta lipoprotein ratio & 28. Father alive or dead \\
14. Age of father at death & & \\
15. Age of mother at death & & \\
\hline
\end{tabular}

according to the Registrar General's Classification of Occupations. ${ }^{8}$ The amount of physical activity of each subject was derived from information about the nature of his work, the distance walked or cycled to and from work each day, and the estimated number of leisure hours a week spent on physical activities (see Appendix).

The amount of alcohol consumed was graded as follows: Teetotal always; teetotal now; takes alcohol less often than once a week; once a week or more often but not daily; daily.

Arcus lipoides was graded into: Grade $0=$ absent; Grade 1 = incomplete; Grade 2 = complete in both eyes.

An electrocardiographic examination was carried out on each subject. The standard 12 leads were recorded with the subject lying down and after a three-minute stepping exercise at a standardised work rate of $350 \mathrm{~kg} \mathrm{miles} / \mathrm{min} .^{9}$ All the ECGs were read by one cardiologist and coded according to the Minnesota code. ${ }^{1011}$ Three types of ECG abnormality were analysed in relation to the future development of CHD: Minn I 1-3 (Q/QS changes); Minn IV 1-3 (S-T depression); and Minn V 1-3 (T-wave changes).

THE FOLLOW-UP

After the initial examinations, the subsequent CHD status of the subjects was ascertained in three ways:

(a) The Registrar General of Northern Ireland was provided with a list of the names and addresses of all the subjects and notified us from time to time of deaths and causes of death of men in our sample.

(b) Each subject was sent a letter annually inquiring about any pain in the chest and, if present, its relation to exertion.

(c) MG visited the general practices periodically and examined the records of all the subjects and consulted the GP when the reply to the letter suggested the development of angina. For subjects who had moved out of the district the names of their new GPs were obtained and inquiries sent to them.

Subjects suspected of having angina pectoris or cardiac ischaemia were referred to a medical outpatient department and diagnosed as such only on the opinion of a consultant physician. Similarly, with the exception of two sudden deaths, subjects were included in the myocardial infarction group only after they had been so diagnosed by a hospital consultant. Of the two sudden deaths ascribed to CHD, one was confirmed at necropsy, and in the case of the other, who died suddenly while on holiday in the Irish Republic, the diagnosis was based on the history.

\section{Results}

INCIDENCE OF CHD

Of the 1202 subjects judged to be free of clinical CHD at the initial examination, 27 had died of other diseases by the end of the five-year follow-up period and three men could not be traced. This left 104 men who developed CHD, 'the developers', and 1068 who remained free of it, the 'non-developers' (Table 5). These two groups have been compared in relation to risk factors. Developers were defined as men who developed angina pectoris or cardiac ischaemia or who had a proven myocardial infarction. The 104 developers included 49 who developed angina alone, or cardiac ischaemia (five), and 55 (15 fatal) who developed myocardial infarction with or without preceding or succeeding angina. The morbidity rate in this sample was therefore $1.7 \%$ per annum and the mortality rate $0.25 \%$ per annum.

Table 5 CHD status after five years of the 1202 men included in the study

\begin{tabular}{|c|c|c|}
\hline No evidence of CHD & & 1068 \\
\hline $\begin{array}{l}\text { Developed CHD } \\
\text { Myocardial infarction (died of MI:15) } \\
\text { Angina (or cardiac ischaemia: five cases) only }\end{array}$ & $\begin{array}{l}55 \\
49\end{array}$ & 104 \\
\hline Died of other causes & & 27 \\
\hline Untraced & & 3 \\
\hline Total & & 1202 \\
\hline
\end{tabular}

COMPARISON OF ANGINAL AND MI CASES Although it is generally believed that angina pectoris and myocardial infarction are usually different manifestations of the same disease, it is possible that the same risk factors do not apply to both conditions or do not apply equally. It was considered desirable, therefore, to examine the mean values of the continuous variables and the distributions of the 
Table 6 Mean initial values of the continuously distributed factors in those who developed angina only and those who developed myocardial infarction with or without angina

\begin{tabular}{|c|c|c|c|c|}
\hline \multirow[b]{2}{*}{ Factors } & \multicolumn{2}{|l|}{ Mean levels } & \multirow[b]{2}{*}{$\begin{array}{l}\text { Difference } A-B \\
( \pm S E)\end{array}$} & \multirow[b]{2}{*}{$\mathbf{t}$} \\
\hline & $\begin{array}{l}\begin{array}{l}A \\
\text { Developed } \\
\text { angina }\end{array} \\
n=49\end{array}$ & $\begin{array}{l}\text { B } \\
\text { Developed } \\
\text { myocardial } \\
\text { infarction } \\
n=55\end{array}$ & & \\
\hline Age (years) & $53 \cdot 51$ & $53 \cdot 53$ & $-0.02 \quad(0.67)$ & 0.03 \\
\hline Total tobacco consumption $(\mathrm{kg})$ & $199 \cdot 54$ & 199.44 & $+0.10 \quad(33.33)$ & 0.003 \\
\hline Current daily tobacco consumption (g) & $17 \cdot 33$ & 16.64 & $+0.69 \quad(2.30)$ & 0.30 \\
\hline Total years of smoking & 27.67 & 28.95 & $-1 \cdot 28$ & 0.48 \\
\hline Systolic blood pressure $(\mathrm{mm} \mathrm{Hg}$ ) & $138 \cdot 37$ & 140.73 & $(4 \cdot 63)$ & $0 \cdot 51$ \\
\hline Diastolic blood pressure (mm $\mathrm{Hg}$ ) & $87 \cdot 14$ & 86.09 & $(2.63)$ & 0.40 \\
\hline Neuroticism (Heron 1 score) & 6.90 & 5.93 & $(0.66)$ & 1.46 \\
\hline Introversion (Heron 2 score) & $5 \cdot 32$ & $5 \cdot 58$ & $-0.26 \quad(0.46)$ & 0.57 \\
\hline Weight (kg) & $75 \cdot 57$ & $74 \cdot 44$ & $+1 \cdot 13 \quad(2 \cdot 09)$ & $0 \cdot 54$ \\
\hline Height $(\mathrm{cm})$ & $169 \cdot 67$ & $170 \cdot 76$ & $(1 \cdot 03)$ & $1 \cdot 06$ \\
\hline Skinfold thickness (mm) & $15 \cdot 59$ & $14 \cdot 67$ & $(1 \cdot 21)$ & 0.76 \\
\hline Serum cholesterol $(\mathrm{mg} / 100 \mathrm{ml})$ & $227 \cdot 84$ & $227 \cdot 20$ & +0.64 & $0 \cdot 10$ \\
\hline Serum total fatty acids (mmol/l) & $13 \cdot 89$ & 14.48 & -0.59 & 0.81 \\
\hline Alpha beta lipoprotein ratio & 0.71 & 0.74 & -0.03 & 0.55 \\
\hline Age of father at death (years) & $63 \cdot 38$ & $66 \cdot 38$ & $-3 \cdot 02$ & $1 \cdot 03$ \\
\hline Age of mother at death (years) & $66 \cdot 48$ & $68 \cdot 49$ & $-2 \cdot 01$ & 0.61 \\
\hline
\end{tabular}

categorical variables in these two groups to see whether there were any significant differences between them.

The mean initial values of the continuous variables are shown in Table 6 for these two groups. None of the mean values differ significantly in the two affected groups.

The distributions of the categorical variables in the angina and myocardial infarction groups were also examined and were shown not to differ significantly except for the socioeconomic group. The difference in this case was due to the fact that the group described as 'employers and managers' were more likely to develop myocardial infarction than angina pectoris alone when compared with the whole group $\overrightarrow{0} \vec{\sim}$ With this single exception, our findings therefor $\vec{D} \omega$ supported the accepted view that angina of effort and myocardial infarction are manifestations of the same disease process and that any risk factors which are identified will apply to both. In all subsequent Tables the two groups are therefore amalgamated.

COMPARISON OF CONTINUOUS FACTORS IN DEVELOPERS AND NON-DEVELOPERS

Table 7 shows the mean values of the continuous factors at the initial examination in those who

Table 7 Mean initial values of continuously distributed factors in those who developed CHD and those who did not

\begin{tabular}{|c|c|c|c|c|c|}
\hline \multirow[b]{2}{*}{ Factors } & \multicolumn{2}{|l|}{ Mean levels } & \multirow{2}{*}{\multicolumn{2}{|c|}{$\begin{array}{l}\text { Difference } A-B \\
( \pm S E)\end{array}$}} & \multirow[b]{2}{*}{$\mathbf{t}$} \\
\hline & $\begin{array}{l}\text { A } \\
\text { Developed } \\
C H D \\
n=104\end{array}$ & $\begin{array}{l}B \\
\text { Did not develop } \\
C H D \\
n=1068\end{array}$ & & & \\
\hline Age (years) & $53 \cdot 52$ & $53 \cdot 16$ & +0.36 & $(0 \cdot 36)$ & $1 \cdot 00$ \\
\hline Total tobacco consumption & 199.48 & $156 \cdot 77$ & +42.71 & $(14 \cdot 48)$ & $2 \cdot 95^{*}$ \\
\hline Current daily tobacco consumption (g) & 16.96 & $14 \cdot 19$ & $+2 \cdot 77$ & $(1 \cdot 19)$ & $2 \cdot 32^{*}$ \\
\hline Total years of smoking & $28 \cdot 35$ & $24 \cdot 60$ & +3.75 & $(1.46)$ & $2 \cdot 56^{*}$ \\
\hline Systolic blood pressure (mm Hg) & $139 \cdot 62$ & $135 \cdot 14$ & $+4 \cdot 48$ & $(2 \cdot 19)$ & $2 \cdot 04^{*}$ \\
\hline Diastolic blood pressure (mm $\mathbf{~ H g}$ ) & 86.59 & 83.39 & $+3 \cdot 20$ & $(1 \cdot 23)$ & $2 \cdot 60^{*}$ \\
\hline Neuroticism (Heron 1 score) & $6 \cdot 39$ & $5 \cdot 86$ & +0.53 & $(0 \cdot 36)$ & 1.49 \\
\hline Introversion (Heron 2 score) & $5 \cdot 46$ & $5 \cdot 60$ & -0.14 & $(0 \cdot 26)$ & $0 \cdot 54$ \\
\hline Weight (kg) & 74.97 & $74 \cdot 24$ & +0.73 & $(1 \cdot 11)$ & 0.66 \\
\hline Height $(\mathrm{cm})$ & $170 \cdot 25$ & $171 \cdot 71$ & -1.46 & $(0 \cdot 66)$ & $2 \cdot 21^{*}$ \\
\hline Skinfold thickness (mm) & $15 \cdot 11$ & $14 \cdot 12$ & +0.99 & $(0 \cdot 57)$ & 1.75 \\
\hline Serum cholesterol $(\mathrm{mg} / 100 \mathrm{ml})$ & $227 \cdot 50$ & $220 \cdot 93$ & +6.57 & $(3 \cdot 17)$ & $2 \cdot 07^{*}$ \\
\hline Serum total fatty acids (mmol/l) & $14 \cdot 20$ & $13 \cdot 67$ & +0.53 & $(0 \cdot 30)$ & $1 \cdot 79$ \\
\hline Alpha beta lipoprotein ratio & 0.724 & $0 \cdot 772$ & -0.048 & $(0.03)$ & $1 \cdot 80$ \\
\hline Age of father at death (years) ${ }^{* *}$ & 64.91 & $66 \cdot 53$ & -1.62 & $(1.62)$ & $1 \cdot 00$ \\
\hline Age of mother at death (years) ${ }^{* * *}$ & $67 \cdot 52$ & $67 \cdot 23$ & +0.29 & $(1 \cdot 71)$ & $0 \cdot 17$ \\
\hline
\end{tabular}

* Significant where $t=2 \quad P=0.05, \quad t=3 \quad P=0.01$.

** 1015 deceased fathers.

*** 851 deceased mothers. 
developed the disease and in those who did not. The following were significantly greater in the developers:

Total tobacco consumption.

Current tobacco consumption.

Duration in years of smoking.

Systolic blood pressure.

Diastolic blood pressure.

Serum cholesterol.

The mean height of the developers was significantly less than that of the non-developers.

No significant relationship was found between the risk of developing CHD and (mean) age, neuroticism score, introversion score, weight, skinfold thickness, serum total fatty acids, alpha beta lipoprotein ratio, and age of either mother or father at death. The lack of relationship to age may be explained by the narrow age band (10 years) of the subjects.

COMPARISON OF CATEGORICAL FACTORS IN DEVELOPERS AND NON-DEVELOPERS

Economic position

Table 8 shows that those who were working at the time of the initial examination were significantly less likely to develop CHD than the group of men who were unemployed or had been off work due to non-CHD sickness for more than six months or who had retired prematurely.

\section{ECG findings}

Table 9 summarises the ECG findings. Of the 74 men who had Q/QS changes at the initial examination 11 (14.9\%) developed CHD, whereas of the 1098 men without Q/QS changes only $93(8.5 \%)$ developed CHD. This difference did not, however, reach the conventional level of statistical significance. Those who had T-wave changes or S-T depression at the initial examination were significantly more likely to develop CHD in the next five years than those who did not have these abnormalities.

The risk of developing CHD with particular combinations of these three ECG abnormalities rose from $79(7.83 \%)$ in the 1009 men with none of these ECG changes at the initial examination to three (50\%) of the six men who had all three. A hierarchical log-linear analysis of Table 9 revealed that the probability of developing CHD depended mainly on the presence of $\mathrm{S}-\mathrm{T}$ depression. The expected numbers on this model are shown in brackets. There are no statistically significant departures between

Table 8 Distribution of developers and non-developers by economic position

\begin{tabular}{|c|c|c|c|c|c|}
\hline \multirow{3}{*}{$\begin{array}{l}\text { CHD status } \\
\text { after five years }\end{array}$} & \multicolumn{4}{|c|}{ Economic position } & \multirow[b]{2}{*}{ Total } \\
\hline & 1 & 2 & 3 & 4 & \\
\hline & No. (\%) & No. (\%) & No. (\%) & No. (\%) & No. \\
\hline $\begin{array}{l}\text { Developers } \\
\text { Non-developers }\end{array}$ & $\begin{array}{rr}94 & (8.4) \\
1024 & (91.6)\end{array}$ & $\begin{aligned} 5 & (16 \cdot 7) \\
25 & (83 \cdot 3)\end{aligned}$ & $\begin{aligned} 4 & (26 \cdot 7) \\
11 & (73 \cdot 3)\end{aligned}$ & $\begin{array}{ll}1 & (12 \cdot 5) \\
7 & (87 \cdot 5)\end{array}$ & $\begin{array}{rr}104 & (8 \cdot 9) \\
1067 & (91 \cdot 1)\end{array}$ \\
\hline Total & $1118(100)$ & $30(100)$ & $15(100)$ & $8(100)$ & $1171(100)$ \\
\hline
\end{tabular}

$\chi^{2}=6.28 \quad$ df $=3 \quad 0.02>P>0.01$

1. Employed.

2. Unemployed at time of interview.

3. Off sick for $>6$ months (not CHD).

4. Retired.

2,3 , and 4 grouped together for $\chi^{2}$.

Table 9 Distribution of developers and non-developers by three ECG abnormalities

\begin{tabular}{|c|c|c|c|c|c|c|c|c|}
\hline \multicolumn{3}{|c|}{ ECG abnormality } & \multirow{2}{*}{\multicolumn{2}{|c|}{ Non-developers }} & \multirow{2}{*}{\multicolumn{2}{|c|}{ Developers }} & \multirow{2}{*}{$\begin{array}{l}A \\
\%\end{array}$} & \multirow{2}{*}{$\begin{array}{l}B \\
\%\end{array}$} \\
\hline$Q Q S$ & $T$-wave & $S-T$ depression & & & & & & \\
\hline - & - & - & 930 & $(925.52)^{*}$ & 79 & $(83.48)$ & $7 \cdot 83$ & $7 \cdot 83$ \\
\hline+ & - & - & 49 & $(50.45)$ & 6 & $(4 \cdot 55)$ & 10.91 & \\
\hline- & + & - & 44 & $(45 \cdot 86)$ & 6 & $(4 \cdot 14)$ & 12.00 & $12 \cdot 31$ \\
\hline- & - & + & 21 & $(19 \cdot 27)$ & 4 & $(5.73)$ & $16 \cdot 00$ & \\
\hline+ & + & - & 8 & (9.17) & 2 & $(0.83)$ & 20.00 & \\
\hline+ & - & + & 3 & $(2 \cdot 31)$ & 0 & $(0.69)$ & 0.00 & $22 \cdot 22$ \\
\hline- & + & + & 10 & $(10.79)$ & 4 & $(3 \cdot 21)$ & $28 \cdot 57$ & \\
\hline+ & + & + & 3 & $(4.63)$ & 3 & $(1 \cdot 38)$ & $50 \cdot 00$ & $50 \cdot 00$ \\
\hline \multicolumn{3}{|c|}{ All subjects } & 1068 & & 104 & & & $8 \cdot 87$ \\
\hline
\end{tabular}

$+=$ present $\quad \mathrm{A}=\%$ developed

- = absent $\quad$ B $=$ grouped $\%$ developed

- Expected numbers in brackets (see text). 
observation and expectation $\left(\chi^{2}=7 \cdot 53, \mathrm{df}=6\right.$, $P>0.05)$. It should be emphasised that the majority of the men who developed CHD (79 out of 104) showed no ECG abnormalities at the initial examination.

\section{Other categorical factors}

No relationship was found between the development of CHD and the individual distributions of the following categorical variables: social class, socioeconomic group, physical activity, frequency of alcohol consumption, presence or absence of arcus lipoides, or whether the subject's father or mother was alive or dead.

\section{MULTIVARIATE ANALYSIS}

With relatively few developed cases of $\mathrm{CHD}$ the hierarchical classification of the data in the measured factors is impracticable. Therefore, to reduce the number of variables for multivariate study on objective and reproducible criteria, a stepwise forward linear discriminant analysis was carried out on 13 continuous and 10 categorical variables (nos. 1 to 13 and 16 to 25 , Table 4). Before the analysis the categorical variables were given an appropriate design matrix parameterisation. The resulting discriminant function, here formally equivalent to a correlated main effects model, contained only four variables: S-T depression (partial $F=11.24$ ); total tobacco consumption (partial $F=10 \cdot 45$ ); diastolic blood pressure (partial $\mathrm{F}=5.71$ ); and height (partial $F=4 \cdot 13)$. Using these four variables, the linear discriminant explained only $16 \cdot 51 \%$ of the total sums of squares available for partitioning and on this criterion must be considered an inadequate predictive tool. Furthermore, it is known that possible interactions between the variables are ignored by this technique.

In order to investigate further the probability of developing $\mathrm{CHD}$ in the five-year period, the simultaneous distribution of the data in the four factors selected by the discriminant function analysis was subjected to hierarchical log-linear analysis. Before analysis the three continuous variables were categorised as: diastolic blood pressure $<80,80$ to 99.99, 100+; height $\leqslant 171 \mathrm{~cm}$ (mean height for sample), $172+\mathrm{cm}$; total tobacco consumption $\leqslant 439$ (mean grams lifetime consumption/365), $440+$. The severity of this categorisation merely reflects the small number of developers available for analysis.

The hypothesis that the probability of developing CHD is independent of the four factors studied was easily rejected $\left(\chi^{2}=52 \cdot 16, \mathrm{df}=23, \mathrm{P}<0 \cdot 05\right)$. The model containing all possible two factor interaction terms between CHD and the other factors was found to fit the data satisfactorily $\left(\chi^{2}=24 \cdot 65, \mathrm{df}=18\right.$, $P>0.05)$ although further investigation revealed the height term to be redundant. Accordingly, Table 10 shows the conditional probabilities of developing CHD in the next five years derived from the reduced model which excludes the height by CHD interaction term.

The maximum risk of development $(0.3732)$ occurs in men with S-T depression and above average total tobacco consumption and a diastolic bloof pressure of $100+$. For these men the risk of $\omega$ developing CHD is approximately four times greate $\mathrm{f}_{\mathrm{D}}$ 음 than that noted in the study population as a whole, if $-\overrightarrow{8}$ which the undifferentiated, or random, risk was $8 \cdot 87 \%$. The minimum risk occurred among men wit no S-T depression whose total tobacco consumptio was average, or less than average, and whose diastolita pressures were less than 80 . In general, the probability of development increased with the presence of S-T depression, greater than average total tobacco consumption, and rising diastolic pressure. From Table 10 it is apparent that S-T depression was the major determinant: with one exception (average or less than average total tobacco consumption and diastolic pressure $<80$ ), the conditional probabilities of development were higher-on average 2.5 times greater on a corresponding cell basis-when this ECG abnormality was present. Formal testing, based on

Table 10 Estimated* conditional probabilities of development of CHD by $S-T$ depression, total tobacco consumption, height, and diastolic blood pressure

\begin{tabular}{|c|c|c|c|c|c|c|c|c|}
\hline \multirow{3}{*}{$\begin{array}{l}\text { Diastolic } \\
\text { blood pressure } \\
(\mathrm{mm} \mathrm{Hg})\end{array}$} & \multicolumn{4}{|l|}{$S-T(+)$} & \multicolumn{4}{|l|}{$S-T(-)$} \\
\hline & \multicolumn{2}{|c|}{ Smoking** (+) } & \multicolumn{2}{|c|}{ Smoking (-) } & \multicolumn{2}{|c|}{ Smoking (+) } & \multicolumn{2}{|c|}{ Smoking (-) } \\
\hline & $H t(+)$ & $H t(-)$ & $H t(+)$ & $H t(-)$ & $H t(+)$ & $H t(-)$ & $H t(+)$ & $H t(-)$ \\
\hline$<80$ & 0.2349 & 0.2349 & 0.1282 & 0.1282 & 0.0872 & 0.0872 & 0.0438 & 0.0438 \\
\hline $80-99 \cdot 99$ & 0.3012 & 0.3012 & $0 \cdot 1711$ & $0 \cdot 1711$ & 0.1182 & 0.1182 & 0.0604 & 0.0604 \\
\hline $100+$ & 0.3732 & 0.3732 & 0.2219 & 0.2219 & $0 \cdot 1563$ & $0 \cdot 1563$ & 0.0815 & 0.0815 \\
\hline
\end{tabular}

$+=$ present, or greater than average level.

$-=$ absent, or less than or equal to average level.

* = on the basis of a log-linear model (see text).

** = total tobacco consumption. 
the degradation of the $\chi^{2}$ goodness-of-fit statistic, when the two factor interaction terms in the reduced model were systematically deleted, confirmed the prominence of S-T depression, and ranked total tobacco consumption before diastolic blood pressure in order of importance.

\section{Discussion}

The incidence of CHD in this study was on average $1.7 \%$ per annum, a figure similar to that of $1.5 \%$ per annum found in the Framingham study ${ }^{12}$ for men aged $45-62$.

Like several other investigations, ${ }^{13}$ this one has shown that the following characteristics, considered singly, are significantly and positively associated with the risk of developing CHD: tobacco consumption, systolic and diastolic blood pressure, serum cholesterol, and certain ECG abnormalities. We also found that height was significantly and negatively associated with this risk. In general, these risk factors seldom exert mutually independent effects and using a combination of multivariate methods the probability of a CHD-free man developing the disease within five years was found to depend on only three characteristics measured at initial examination. These were S-T depression in the ECG, total lifetime tobacco consumption, and diastolic blood pressure. While the chance of development was maximal $(0.3732)$ when these three factors assumed their uppermost values, the absolute risk of developing CHD was still small, over the period of observation. Care must be exercised when interpreting the findings of longitudinal studies. The results are conditional on the particular population studied and on the length of the follow-up period and, conceivably, different results may obtain later in this study as more CHD-free men develop the condition. Also, in this study measurements made at a single examination are related to the future development of $\mathrm{CHD}$; consequently there is no evaluation of subsequent risk factor modification. It is probable that some men who would initially have satisfied the entry criteria for the prospective study had developed the condition by the time they were contacted and were therefore excluded. The actual incidence of the condition may therefore be higher than the figure reported. The relatively small numbers developing CHD precluded the simultaneous investigation of more than four risk factors by hierarchical methods, and while the adopted analytical compromise appears reasonable it cannot be considered exhaustive.

It would seem that with current knowledge the majority of cases of CHD are unpredictable. However, it could be argued that, since prediction is often based on only one initial examination, more frequent follow-up examinations for selected characteristics, together with longer periods of observation, would make possible the compilation of more accurate prognostic indices. It could also be argued that the rather poor prediction which has been found so far indicates that we have identified only some of the characteristics associated with the development of $\mathrm{CHD}$, and that there must be other more significant but as yet undiscovered factors which are concerned in its aetiology.

We wish to thank Professor E. A. Cheeseman and Dr. Desmond Merrett for advice in the planning and design of the study and Professor W. G. Irwin and the following general practitioners for their co-operation and access to their patients: Drs. D. Cuming, G. A. Donaldson, H. W. Dunn, W. Rutherford, N. D. Wright, J. D. Henderson, C. W. Musgrave, F. C. Gormley, F. E. Pollock, N. Bamford, M. D. Bamber, W. R. Rowney, J. D. Price, G. T. C. Hamilton, J. B. Bowden, R. M. Pritchard. Mr. R. H. McClarin carried out the laboratory estimations, Dr. Evan Fletcher read and coded all the electrocardiograms, and the Registrar General for Northern Ireland provided information on the causes of death of the subjects who died during the course of the study.

The Nuffield Provincial Hospitals Trust, the Northern Ireland Hospitals Authority and the British Heart Foundation supported this study with generous grants over a number of years.

Reprints from Professor J. Pemberton, Northern Consortium for Training in Community Medicine, Fulwood House, Old Fulwood Road, Sheffield S10 3 TH.

\section{Appendix}

\section{Estimate of physical activity of each subject}

The men were ranked $1-3$ for occupational activity using the classification (1, 3, and 5) prepared by Dr. R. Murray and Dr. D. Turner for use in the National Necropsy Survey. ${ }^{14}$ The classification is in terms of the physical activity habitually and typically involved in the given occupation.

$$
\begin{aligned}
& \text { Light work }=1 \\
& \text { Active work }=2 \\
& \text { Heavy work }=3
\end{aligned}
$$

The men were ranked $1-3$ for leisure activity from the sum of the leisure hours spent in physical 
activities each week and the hours spent walking or cycling to and from work each week. Three miles walking or nine miles cycling were taken as equivalent to one hour of physical activity.

Under five hours leisure activity a week

Five to 9 hours inclusive leisure activity a week

Ten hours or more leisure activity a week

The two ranks were summed to give a total activity score.

\section{References}

${ }^{1}$ Rose G. The diagnosis of ischaemic heart pain and intermittent claudication in field surveys. Bull WHO 1962; 27: 645-58.

${ }^{2}$ Heron A. A two-part personality measure for use as a research criterion. Br J Psychol 1956; 47: 243-51.

${ }^{3}$ Tanner JM. Growth at Adolescence. 2nd ed. London: Oxford University Press, 1962: 241.

${ }^{4}$ Albrink MJ. Lipoprotein pattern as a function of total triglyceride concentration of serum.J Clin Invest 1961; 40: $536-44$.
${ }^{5}$ MacIntyre I, Ralston M. Direct determination of serum cholesterol. Proceedings of the Biochemical Society. Biochem J 1954; 56: xliii.

${ }^{6}$ Albrink MJ. The microtitration of total fatty acids of serum with notes on the estimation of triglycerides. $J$ Lipid Res 1959; 1: 53-9.

${ }^{7}$ Kernohan RJ, Neely RA. The effects of atromid on the alpha beta lipoprotein ratio in coronary disease. $J$ Atherosclerosis Res 1963; 3: 518-24.

${ }^{8}$ Registrar General. Classification of Occupations. London: HMSO, 1966.

${ }^{8}$ Hugh-Jones P, Lambert AV. A simple standard exercise test and its use for measuring exertion dyspnoea. $\mathrm{Br} \mathrm{Med}$ J 1952; 1: 65-71.

${ }^{10}$ Blackburn H, Keys A, Simpson E, Rautaharju P, Punsar S. The electrocardiogram in population studies. Circulation 1960; 21: 1160-75.

${ }^{11}$ Rose G, Blackburn H. Cardiovascular Survey Methods. Geneva: WHO, 1968: 5-188.

${ }^{12}$ Kannel WB, Dawber TR, Kagan A, Revotskie N, Stokes J. III. Factors of risk in the development of coronary heart disease-six years follow-up experience. Ann Intern Med 1961; 55: 33-50.

${ }^{13}$ Pooling Project Research Group. Relationship of blood pressure, serum cholesterol, smoking habit, relative weight, and ECG abnormalities to the incidence of major coronary events. J Chronic Dis 1978; 31: 201-306.

${ }^{14}$ Morris JN, Crawford MD. Coronary heart disease and physical activity of work. Br Med J 1958; 2: 1485-96. 